Sukhomlinov, A.B.

ShimUkraine, Ltd., Kyiv

\title{
NEW RESEARCH INSTRUMENTS MANUFACTURED BY SHIMADZU CORPORATION
}

The paper deals with new models of research instruments manufactured by Japanese corporation SHIMADZU, including liquid and gas chromatographs, mass spectrometers, IR spectrophotometer, energy dispersive X-ray spectrometers, particle size analyzer, and micro hardness tester. The special attention has been paid to enhancement of performance specifications.

Key words: chromatograph, mass spectrometer, spectrophotometer, analyzer, and measurement.

Insofar as detailed outlook of research instruments manufactured by SHIMADZU Corporation (Japan) was made two years ago (Science and Innovation, 8, 2, 48-57 (2012)), it seems appropriate to focus the reader's attention only on those devices which appeared in the market after the above mentioned publication.

During this period, the corporation focused its attention mostly on new models of high-speed liquid chromatography mass spectrometers with triple quadruple. Two models released in 2012 and 2013 (LCMS-8040 and LCMS-8050) were appreciated immediately after their first demonstration to PITTCON visitors and, in a short while, appeared in laboratories. However, before giving information about mass spectrometers it is necessary to emphasize the importance of basic chromatographic system LC-30A developed shortly before, which specifications allow for full manifestation of capabilities of new gas chromatography mass spectrometers. The SHIMADZU liquid chromatograph, model LC-30A, was firstly demonstrated at PITTCON2010 exhibition and currently remains an unsurpassed tool in the field of chemical analysis.

(c) SUKHOMLINOV, A.B., 2014
In 2011, the Instrument Committee of the Russian Academy of Sciences recognized this device the best research instrument of the year. The $\mathbf{L C}$ 30A liquid chromatographer is a versatile modular system for ultrafast high performance liquid chromatography, which allows the users to do ultrafast chromatography. This possibility is provided by technical parameters of its units, primarily, by the pump. This was discussed in detail in the aforementioned outlook, as well as in several other publications. It should be noted that, in 2012, a new modification of chromatograph LC-30 appeared. It contains a new autosampler SIL-30ACMP and a new thermostat SRT-30AS. The SIL-30ACMP autosampler is characterized by a set of features the main of which is fast injection. The injection time is 7 seconds and the period between successive analytical measurements is 14 seconds. This characteristic is particularly important for switching to fast chromatography and chromatography-mass spectrometry, which is typical for today's chromatographic practice. The second important characteristic showing the advantage of SIL-30-ACMP autosampler is a very low residual contamination. If the residual contamination was noticeable an extra time would be 


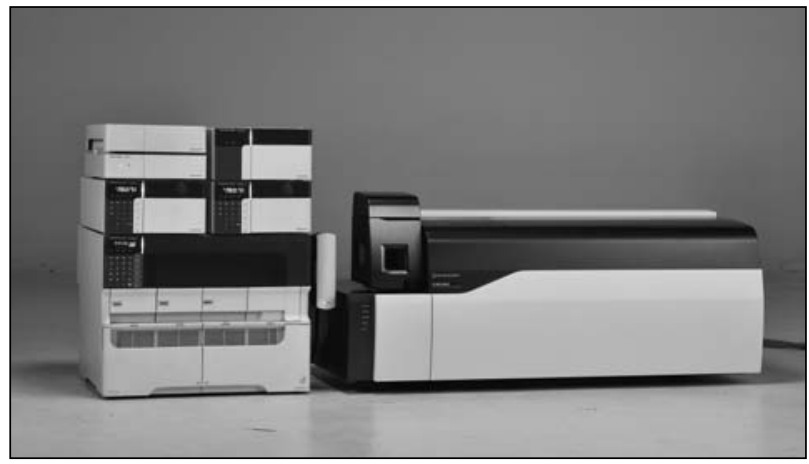

Fig. 1. Liquid chromatography mass spectrometer with triple quadruple, model SHIMADZU LCMS- 8050

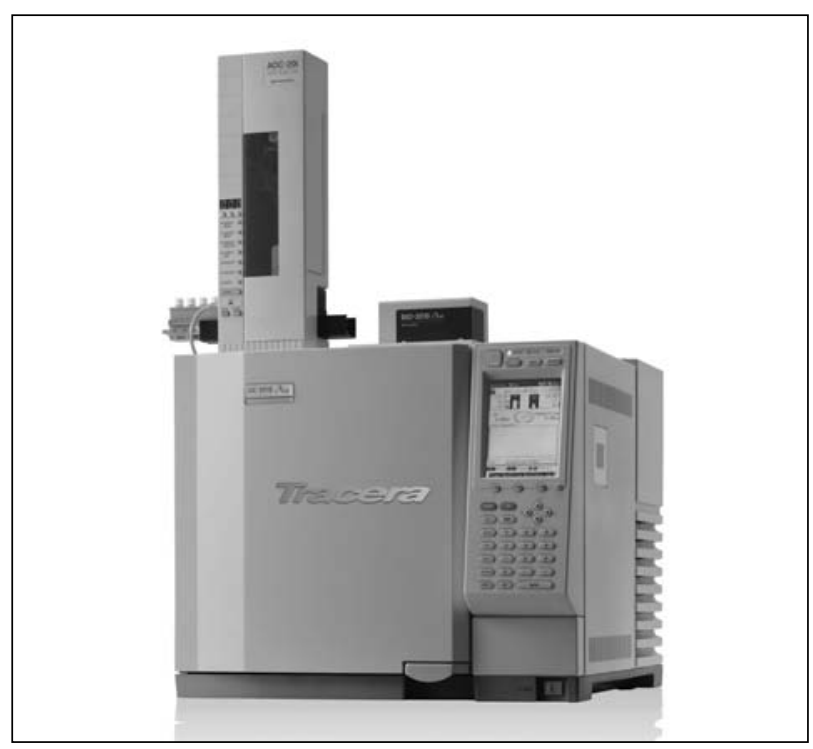

Fig. 2. SHIMADZU Gas Chromatograph, model QP-2010PlusBID Tracera

required to washout the sampler. This is the case for the majority of chromatographers. However, unlike them, the SHIMADZU device does not require rinsing. For example, as a rule, when doing chromatography of solution containing $4 \mathrm{~g} / \mathrm{l}$ of caffeine there is recorded a huge peak and before the next measurement the system is usually washed out. This is not the case for SHIMADZU device: the background recorded after chromatography of this highly concentrated caffeine solution shows virtually no increase over the zero line even without washing, insofar as in case of using
SIL-30ACMP autosampler the residual contamination is only $0.0004 \%$. An important advantage of SIL-30ACMP autosampler is simultaneous installation and simultaneous use of various sample holders by several operators. Six plates can be installed in the autosampler on one plate holder. If the plates with 384 cells are used, totally, 2304 samples can be placed. If the 96-cell plates are used, they can contain 576 samples. And finally, if the holder of $1.5 \mathrm{ml}$ vial is used, then it can hold 324 samples.

It should be noted that the samples can be installed in any of the aforementioned types of holders even in the course of analysis (except for a brief period of injection). If two or three operators need to work on the same device simultaneously, they can install their samples each using his/her type of holder (for example, one uses the tablet, while the other uses the vial).

New STO-30AS thermostat is mounted on the side wall of SIL-30ACMP autosampler. The thermostat position can be adjusted by height and angle (from vertical to horizontal). This is done in order to provide the shortest path from the exit of column to the entrance of detector. Application of STO30AS thermostat is particularly effective for chromatographic systems, including the mass spectrometers. This minimizes peak blur when using the traditional LCMS-2020 mono-quadruple liquid chromatography-mass spectrometer; for LCMS8040 and LCMS-8050 liquid chromatography-mass spectrometer with triple quadruple models it allows the user to maintain ultrafast mode of analysis.

From the above it can be concluded that both the initial configuration and the 2012 modification of LC-30 chromatographic system were designed to provide ultrafast separation process. This in combination with specific features of new design of mass spectrometer with triple quadruple eventually has allowed the researchers to get liquid chromatography-mass spectrometry with such high performance. When creating the LCMS-8040 and LCMS-8050 models the following SHIMADZU patented technologies were used: $U F$-sweeper of ions in colliding cell; UF-switching 
(ultrafast switching of polarity), and UF-lens ion optics design. The simply-structured LCMS8040 chromatography-mass spectrometer of 2012 can be regarded as a routine analytical tool which, nevertheless, has fairly good performance specifications (scanning speed is $15000 \mathrm{amu} / \mathrm{s}$; time of switch from positive and to negative ionization is 0.015 seconds; sensitivity (signal/noise ratio) is over 10 000:1 for $1 \mathrm{pg}$ of reserpine).

The next upgraded LCMS-8050 model of 2013 (Fig.1) has even more impressive features: scanning speed is $30000 \mathrm{amu} / \mathrm{s}$; switching from positive to negative ionization is $0.005 \mathrm{~s}$; sensitivity (signal / noise ratio) exceeds 60 000:1 for 1 pg of reserpine. The instrument ensures reliable detection of chromatographic peaks with a width of less than 1 second. Along with LCMS-8040 and LCMS-8050 the users can receive ready packages of techniques that allow them to avoid a series of routine procedures for optimizing the conditions of chromatographic separation and mass spectrometric measurements. Currently, there are available the technique packages for determining more than 500 individual compounds. The packages include HPLC separation conditions, retention times, parameters for identification of chromatographic peaks, optimized MRM mode settings for each defined compound and report templates to display the qualitative and quantitative results.

New SHIMADZU chromatograph with versatile detector that uses ionization of components to be identified in low-temperature barrier discharge helium plasma (the plasma temperature close to the ambient temperature) is of undoubted interest for the professionals who need gas chromatographs. In accordance with the nature of plasma the new detector was named BID (Barrier discharge Ionization Detector), while the gas chromatograph representing the GC-2010PlusBID system was named TRACERA, due to a high sensitivity of new detector (Fig. 2).

The versatility of this detector means its ability to perform the measurement of concentration of both organic and inorganic components of the sample. The BID-detector sensitivity to the inor-



Fig. 3. SHIMADZU vapor autosampler, model HS-20

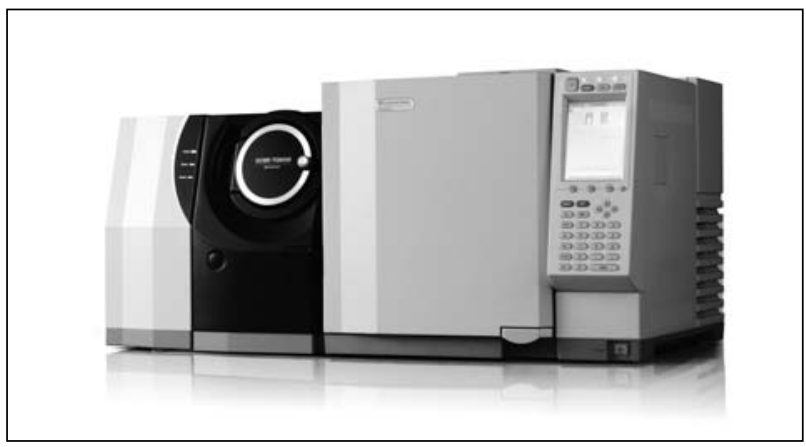

Fig. 4. SHIMADZU gas chromatography-mass spectrometer with triple quadruple, model GCMS-TQ8030

ganic compounds is 100 times higher than that of the conventional thermal conductivity detector; the sensitivity to the organic compounds is twofold higher than that of the conventional flameionization detector.

Thus, for analyzing the mixture containing both organic and inorganic components, instead of using two detectors, it suffices to have one BID-detector, which, in addition, gives higher sensitivity of detection. Also, it is important to note that the detector design does not provide for direct contact between the plasma and the electrodes. Consequently, contamination of electrodes is minimized, which ensures the stability of analysis results.

In 2012, SHIMADZU Corporation released new HS-20 loop-type autosampler for injecting the equilibrium vapor samples into chromatografic 


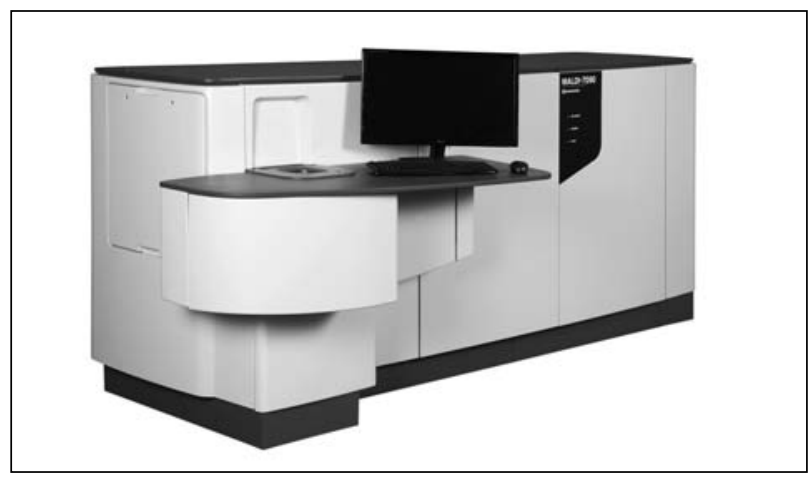

Fig. 5. SHIMADZU mass spectrometer system, model 7090 MALDI-7090

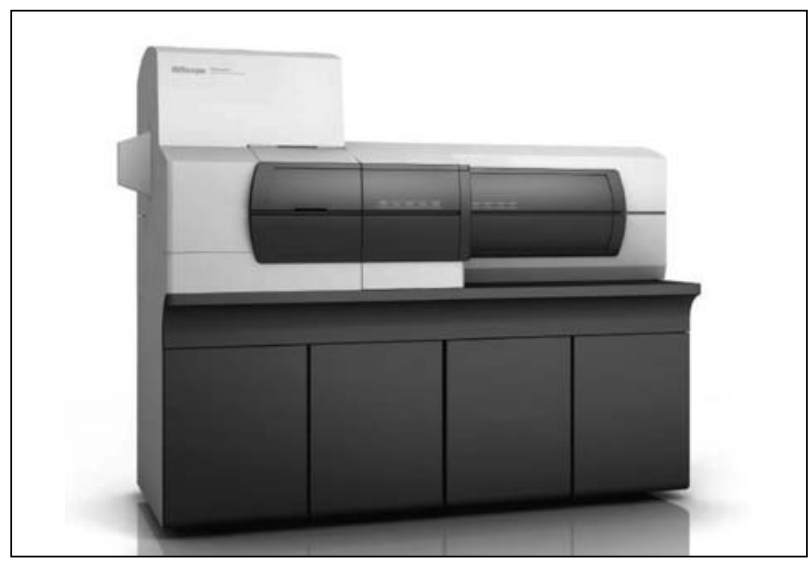

Fig. 6. SHIMADZU visualizing mass microscope, model IMScope

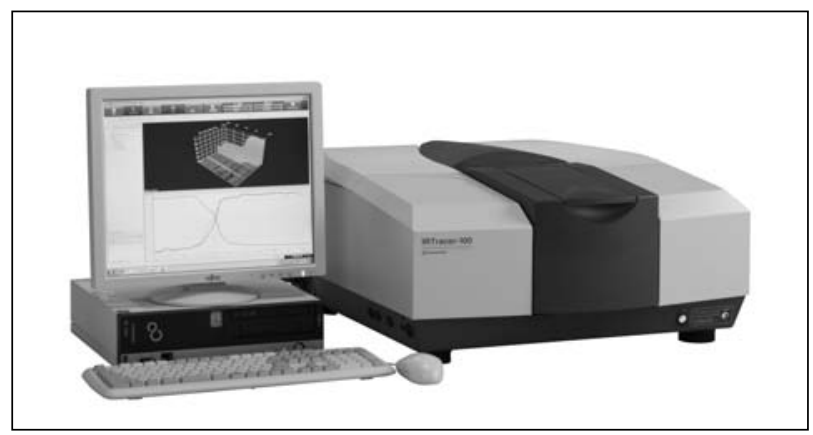

Fig. 7. SHIMADZU FTIR spectrophotometer, model IRTracer-100

system (Fig. 3). The given device is characterized by a wide temperature range (up to $300{ }^{\circ} \mathrm{C}$ ), a large capacity of thermostated unit for samples (holds 12 vials), and by a large total capacity of sample holder (holds 90 vials) as well. For the first time, new SHIMADZU technologies related to tandem mass spectrometry system were used in liquid chromatography mass spectrometry with triple quadruple systems (see above). Having been combined with effective techniques implemented in QP2010 Ultra mono-quadruple gas chromatography mass spectrometer they allowed the engineers to develop a highly sensitive and ultrafast gas chromatography mass spectrometer with triple quadruple GCMSTQ8030 (Fig. 4). This instrument uses both electron impact and chemical ionization. The mass range is $10-1090 \mathrm{amu}$; scanning speed is 20,000 $\mathrm{amu} / \mathrm{s}$. Sensitivity of mass spectrometer in the Scan mode (signal/noise ratio) for $1 \mathrm{pg}$ of octafluoronaphthalene exceeds 600, and that in the MRM mode for $100 \mathrm{pg}$ of octafluoronaphthalene is over 3000. Like the mono-quadruple systems, the TQ8030 device has an option of direct sample injection in ionization unit. Flow velocity through the analytical column may reach $15 \mathrm{ml} / \mathrm{min}$, which allows the researchers to use any type of columns for analysis, including the macro-columns. Furthermore, two columns can be connected simultaneously to the mass spectrometer interface.

Continuing the traditions established by pioneer works of SHIMADZU employee Koichi Tanaka who, in 2002, was awarded with the Nobel Prize in Chemistry for developing a new method of soft ionization of biomolecules in mass spectrometer (MALDI method) a new mass spectrometer MALDI-7090 (Fig. 5) has been developed. It is a highly effective tool for the identification of biomolecules and the study of their structure. The application of new technologies to tandem time-of-flight mass spectrometry yielded an unmatched mass resolution in MS/MS (TOF/TOF) mode, which exceeds 10000 (FWHM). The solid UV laser $(355 \mathrm{~nm})$ operating with a frequency of $2 \mathrm{kHz}$ in MS and MS / MS modes has a programmable focus size (10-100 microns) and a unique life cycle ( 2 billion pulses). The use of unique curved field reflectron, high-resolution ion gate, and high-energy colliding cell $(20 \mathrm{keV})$ provides the most informative mass spectra. 
Another important achievement in the development of MALDI-TOF mass spectrometry is IMScope visualizing mass microscope (Fig. 6). This unique device combines optical microscope for getting high-resolution morphological images and IT-TOF hybrid mass spectrometer with MALDI ionization at atmospheric pressure, which identifies and visualizes the distribution of molecules in different sample areas. The 5 micron spatial resolution allows the user to visualize the distribution of molecules at subcellular level.

Among new developments in the field of optical spectroscopy it is necessary to note IRTracer100 FTIR spectrophotometer (Fig. 7). This ultrafast high-sensitivity device is designed for a wide range of research and applications. The use of MCT detector and Rapid Scan software allows the researchers to record the spectra at a rate of 20 spectra per second, which opens up wide opportunities in the field of kinetic studies. The spectral range is from 240 to $12500 \mathrm{~cm}^{-1}$. The resolution can be set within the range from 0.25 to $6 \mathrm{~cm}^{-1}$. The signal/noise ratio exceeding $60000: 1$ ensures high-sensitive analytical measurements. The AIM-8800IR microscope can be used in combination with this spectrometer for microscopic studies, bioassays, and surface mapping, etc.

As for the X-ray range spectrometry, two new energy-dispersive X-ray fluorescent spectrometers EDX-7000 and EDX-8000 can be of special interest. They are ideal tools for non-destructive elemental analysis of different samples (solid samples, powders, films, fluids) and different sizes (measurement compartment allows the user to place a sample of $300 \times$ $\times 275 \mathrm{~mm}$ with a height of $100 \mathrm{~mm}$ ). Vacuum or helium purge allows the researchers not only to remove the analytical lines of argon, but also to greatly enhance the sensitivity of light elements detection.

The new ultrafast detector does not require cooling by liquid nitrogen. It allows the user to increase the sensitivity of measurements by almost an order of magnitude, to significantly decrease the measurement time and to improve the signal/ noise ratio. To investigate liquids and powder objects there are used cuvettes with windows of

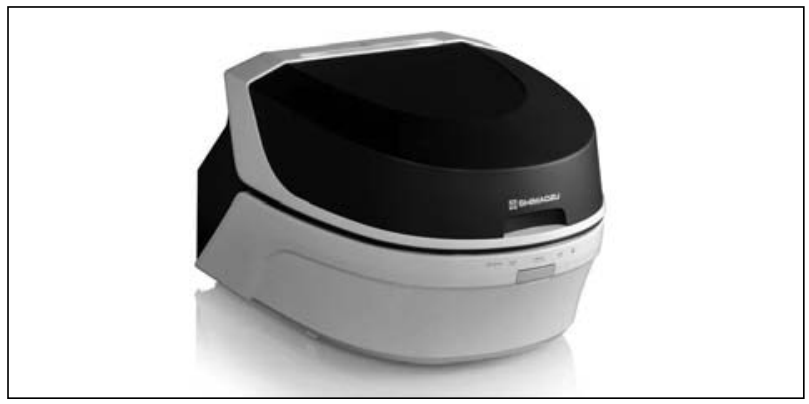

Fig. 8. SHIMADZU energy dispersive X-ray fluorescent spectrometer, model EDX- 8000



Fig. 9. SHIMADZU particle size analyzer, model SALD7500nano

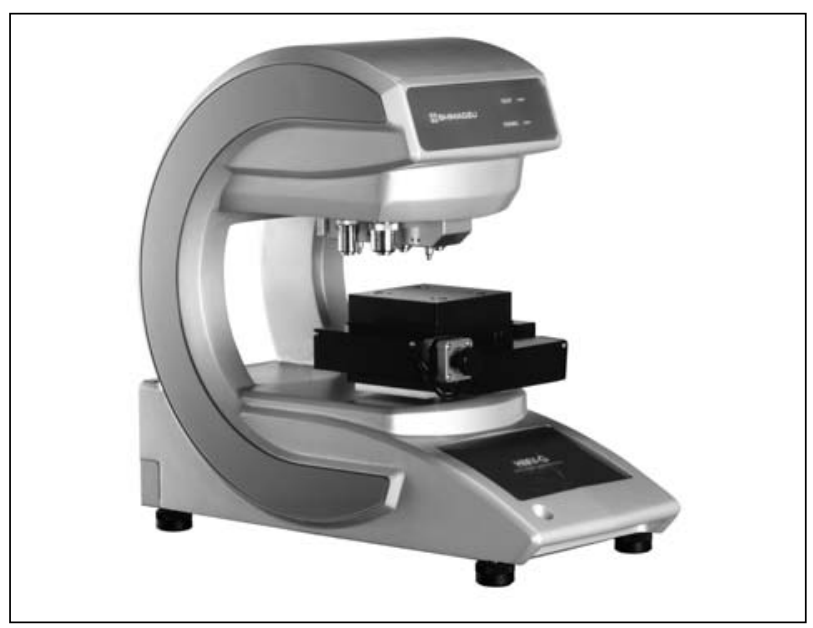

Fig. 10. SHIMADZU micro-hardness measuring instrument, model HMV-G

polymer films which are transparent to X-rays. The cuvettes with samples can be loaded not only manually, but also automatically, using the turret for 12 samples. The EDX-7000 and EDX-8000 in- 
struments allow the researches to study local impregnations in solid samples. For this purpose there are used a set of collimators of different size and a special camera for precise positioning at the point where the sample is to be analyzed. The supplied collimators have the following dimensions: 1; 3 ; 5; and $10 \mathrm{~mm}$. The detector type of is SDD detector with Peltier cooling. The detector resolution is less than $140 \mathrm{eV}$. These models of X-ray fluorescent spectrometer vary in range of elements identified. The range of EDX-7000 model includes the elements from sodium to uranium, whereas the EDX-8000 model (Fig. 8) allows the user to detect also the light elements, with its range including the elements from carbon to uranium.

All the above devices are tools for measuring the sample chemical composition. In addition, SHIMADZU Corporation is known to manufacture the devices for measuring the physical properties of materials.

The latter category includes, for example, particle size analyzers. In 2012, SHIMADZU added a new device, the SALD-7500nano laser diffractometer particle size analyzer (Fig. 9), to the series of well-known models of this type. This device allows the user to measure particle size distributions in the range from 7 to 800 microns. For this both the stationary and the flow measuring cells can be used. An important distinguishing feature of new device is quickness of measurement. The sample analysis lasts nearly one second. This fact (together with possible operation within the nanometer range) allows the researchers to do realtime monitoring of disintegration and agglomera- tion. The group of devices for testing of materials has been extended by a new series of HMV-G hardness measuring instruments (Fig. 10). They are distinguished by a system for automatic change of stress within the range from 0.1 to $20 \mathrm{~N}$. Magnification is $40 \times$. Duration of stress ranges from 5 to 999 seconds.

\section{А.Б. Сухомлинов}

НОВЫЕ ИССЛЕДОВАТЕЛЬСКИЕ ПРИБОРЫ КОРПОРАЦИИ SНIMADZU

Сделан обзор новых моделей научных приборов японской корпорации SHIMADZU. Рассмотрены жидкостные и газовые хроматографы и масс-спектрометры, спектрофотометр ИК-диапазона, энергодисперсионные рентгенфлуоресцентные спектрометры, гранулометрический анализатор, микротвердомер. Особое внимание уделено расширению аналитических возможностей, связанных с техническими характеристиками приборов.

Ключевые слова: хроматограф, масс-спектрометр, спектрофотометр, анализатор, измерение.

О.Б. Сухомлинов

НОВІ ДОСЛІДНИЦЬКІ

ПРИЛАДИ КОРПОРАЦЇ SHIMADZU

Зроблено огляд нових моделей наукових приладів японської корпорації SHIMADZU. Розглянуті рідинні та газові хроматографи та мас-спектрометри, спектрофотометр ІЧ-діапазону, енергодисперсійні рентгенфлуоресцентні спектрометри, гранулометричний аналізатор, мікротвердомір. Особлива увага приділяється розширенню аналітичних можливостей, що пов'язані $з$ технічними характеристиками приладів.

Ключові слова: хроматограф, мас-спектрометр, спектрофотометр, аналізатор, вимірювання.

Received 16.12.13 